\title{
Correlation between the educational environment and burn-out syndrome in residency programs at a university hospital
}

\author{
Julián Llera, M.D., ${ }^{a}$ and Eduardo Durante, M.D. ${ }^{b}$
}

\begin{abstract}
Introduction. The educational environment $(\mathrm{EE})$ is related to satisfaction and achievement. A high prevalence of professional burnout (BO) syndrome has been reported in the residency. The objective of this study was to evaluate the correlation between EE and the presence of burnout in residency programs at a university hospital.

Population and methods. Residents from five programs at Hospital Italiano de Buenos Aires were evaluated. The following items were recorded: specialty, year of residency, sex, nationality and coexistence.

The Postgraduate Hospital Education Environment Measure (PHEEM) that evaluates autonomy, teaching and social support, was used to measure EE. Burnout was measured with the Maslach Burnout Inventory (MBI) that evaluates exhaustion, depersonalization, and personal accomplishment.

Results. Ninety two residents participated. The mean EE was 106.8 (more positive than negative environment). Out of the evaluated residents, $19.6 \%$ showed burnout. There were significant differences in the EE between the populations with and without burnout; mean values: $98.7 \mathrm{vs}$. 108.8 ( $p=0.0056)$.

A negative significant correlation was observed between EE and exhaustion $(r=-0.24)$ and EE and depersonalization $(r=-0.35)$ and a positive significant correlation was found between EE and personal accomplishment $(r=0.44)$. In the same sense, a greater correlation was observed between burnoutand PHEEMautonomy subscale ( $\mathrm{r}=-0.58 ;-0.41$ and 0.46 , respectively).

Conclusions. In the residency, a significant correlation was found between theEEand burnout (reverse with exhaustion and depersonalization, and direct with personal accomplishment). This correlation had greater strength and the same sense for items evaluating autonomy.

Key words: educational environment, professional burnout, residencies.
\end{abstract}

http:/ /dx.doi.org/10.5546/aap.2014.eng.6

\section{INTRODUCTION}

The quality of medical residency programs can be evaluated by the educational environment (EE).

This activity provides information about the context and is related to factors linked to working with other members of the health care team and with situations that have to do with the institutional culture.

Genn and Harden ${ }^{1-3}$ underscored the extraordinary complexity of the environment in medical education. They underlined that if the curriculum of a school of medicine is to be described or evaluated, it is necessary to consider the organizational environment that defines the EE. This evaluation allows to schedule curricular amendments, with a continuous improvement of quality, a mechanism that defines the school of medicine as an organization which learns. ${ }^{4}$

McAleer ${ }^{5}$ lists EE key components (teachers' skills, teaching materials and methods, objectives and evaluation, even social life, etc.) and, as Hutchinson ${ }^{6}$ states in the theory of adult learning, both context and environment are relevant as well as the shared experience and the educational training provided. Extrinsic motivation plays a special role towards the accomplishment of a significant learning.

Besides, it is worth noting the multiple reports describing a high prevalence of indicators of emotional stress, both in medical students and residents. ${ }^{7-10}$ This type of behavioral manifestations are described as professional burnout syndrome. According to Maslach, burnout has three dimensions: emotional exhaustion, depersonalization and cynicism, and a diminished sense of personal accomplishment.

The author created the Maslach Burnout Inventory (MBI), ${ }^{11}$ in which a high score in emotional exhaustion or depersonalization domains is indicative of a clinically significant burnout syndrome. This instrument 
is considered the gold standard to identify burnout. ${ }^{12}$

After reviewing the literature, no studies were found regarding the correlation between $\mathrm{EE}$ and burnout and performed with validated instruments within the context of residency programs.

\section{OBJECTIVE}

To evaluate the correlation between EE and burnout in the residency programs of Hospital Italiano de Buenos Aires.

\section{MATERIAL AND METHODS}

The study was conducted at Hospital Italiano de Buenos Aires in May, 2011. Every residency program of the hospital willing to evaluate all its residents (of all residency years) were invited to participate. A cross-sectional, observational study was designed.

Outcome measures to be analyzed were as follows: sex, specialty, year of residency $\left(1^{\text {st }}, 2^{\text {nd }}, 3^{\text {rd }}\right.$ or $\left.4^{\text {th }}\right)$, coexistence (living alone or accompanied) and nationality (Argentine or foreign). EE and burnout were evaluated.

The Postgraduate Hospital Education Environment Measure (PHEEM) was used to measure EE. This instrument, created by Roff, et al. ${ }^{13}$ consists of 40 items graded on a 0 to 4 Likert scale. It evaluates three domains: perception of role autonomy, perception of teaching and perception of social support. The total score of the questionnaire is a maximum of 160 . The questionnaire and its interpretation are shown in the electronic Annex 1.

The Maslach Burnout Inventory Human Service Survey ${ }^{11}$ was used to evaluate burnout. This survey consists of 22 items, with a score in a Likert scale from 0 to 6 . The questionnaire and its interpretation are shown in the electronic Annex 2.

The main outcome was the correlation between $\mathrm{EE}$ and each MBI subscale. EE measurement was accepted as a continuous outcome measure in agreement with the suggestions proposed by the author of this instrument.

The correlation among the three MBI dimensions and the three PHEEM subscales was analyzed.

EE and burnout evaluation data were analyzed from an overall standpoint and according to demographic outcome measures.

For the statistical analysis, the three MBI dimensions were dichotomized and the presence of burnout was established if the score obtained by each resident was over 26 in the emotional exhaustion subscale (E), over 9 in the depersonalization subscale (D) and below 34 in the personal accomplishment subscale (A).

Subsequently, mean overall results obtained in the educational environment assessment were compared among residents with burnout and without burnout.

In addition, the EE was dichotomized by its median value (109.4) in order to assess the degree of prediction of the environment on burnout. The reliability of the PHEEM was assessed using Cronbach's alpha coefficient.

\section{Sample size}

A pilot study was conducted in our institution in 2010 with both instruments (the PHEEM and the MBI-Human Services Survey) administered to 34 pediatric residents.

Based on preliminary results, the sample size was estimated at 95 survey respondents to obtain an expected correlation coefficient (r) of 0.4 (for the personal accomplishment subscale, that showed a higher correlation with the measurement of environment in the previous pilot study), with a power of $90 \%$ and a $99 \%$ confidence interval, and foreseeing a 10\% loss of data.

\section{Statistical analysis}

Continuous data with normal distribution were analyzed using the $t$ test for difference in mean values, Anova and Pearson's correlation coefficient. Categorical data were assessed using the $\chi^{2}$ test and Fisher's exact test, when applicable. A $p$ value lower than 0.05 was considered significant. Data were analyzed using the Stata 11.0 software, Statistic/Data Analysis, Stata Corp.

\section{Ethical aspects}

Both questionnaires were self-administered in an anonymous and voluntary manner. Data confidentiality was warranted. The hospital's residency programs included were those that accepted to have all their residents participating in the study. Questionnaires were delivered and retrieved by the corresponding chief residents maintaining confidentiality, and they were then submitted to the study authors for analysis.

The study was evaluated and approved by the Research Protocol Ethics Committee of Hospital Italiano de Buenos Aires. 


\section{RESULTS}

The hospital offers 15 residency programs, with a total of 196 residents. Six of these programs agreed to participate (pediatrics, general medicine, family medicine, cardiology and intensive care). Ninety-two surveys were completed $(100 \%$ of pediatrics, family medicine and intensive care residents, $85 \%$ of cardiology residents and $45 \%$ of general medicine residents). The completion rate was $100 \%$, both in relation to the PHEEM and the MBI. Table 1 describes the studied population.

The EE assessment indicated a mean overall environment of 106.8, with a standard deviation of 13.98 (range: 70-155). Such EE measurement expresses a more positive than negative environment (see Annex 1).

The PHEEM subscale assessment is shown in Table 2.

The only demographic outcome measure showing a difference in the EE assessment was the specialty (Anova F-test: $2.96 ; p=0.0241$ ) (results not shown).

Burnout assessment results are shown in Table 3. The Anova for the burnout subscales found significant differences only in terms of specialty and exhaustion (F: $2.85 ; p=0.0283$ ) and depersonalization (F: $3.49 ; p=0.011$ ). No differences were observed in the personal accomplishment analysis.

Depending on the definition accepted for burnout and taking into consideration the three subscales, 18 survey respondents (19.6\%) had values compatible with this syndrome.

After splitting the sample into presence or absence of burnout, both populations showed

TABLE 1. Population of surveyed residents

\begin{tabular}{lcc}
\hline & & Total (\%) \\
\hline Specialty & Pediatrics & $29(31.5)$ \\
& General medicine & $20(21.7)$ \\
& Family medicine & $14(15.2)$ \\
& Cardiology & $14(15.2)$ \\
Year of residency & Adult intensive care & $15(16.3)$ \\
& First & $40(43.5)$ \\
& Second & $19(20.7)$ \\
Sex & Third & $18(19.6)$ \\
& Fourth & $15(16.3)$ \\
Nationality & Female & $64(69.6)$ \\
Coexistence & Male & $28(30.4)$ \\
& Argentine & $80(87)$ \\
& Foreign & $12(13)$ \\
& Living alone & $33(35.9)$ \\
\end{tabular}

significant differences only in the EE assessment (Table 4).

The EE was dichotomized by its median (109.4) for the univariate analysis, and it showed an OR of 6.94 (1.85-26) for the presence of burnout when the EE was below this value.

The univariate analysis found no other association with the rest of the outcome measures.

The analysis of the correlation between the EE (overall and each PHEEM subscale) and each MBI subscale -the main objective of this study- found a negative correlation between the overall environment and exhaustion and depersonalization, while a positive correlation was observed between overall environment and personal accomplishment.

The assessment of each instrument's subscales indicated a significant negative correlation between autonomy and exhaustion and depersonalization, and a positive correlation with accomplishment, even more significant than the correlation with the overall environment. The support subscale was not correlated with burnout and the teaching subscale showed a weak negative correlation with depersonalization and a positive correlation with accomplishment (Table 5).

No question comprehension issues were observed when using the PHEEM. One hundred per cent of surveys were completed with all items. An adequate reliability was demonstrated with a 0.878 Cronbach's alpha coefficient.

TABle 2. Assessment of educational environment. Postgraduate hospital educational environment measure (pheem)

\begin{tabular}{lcccc}
\hline & Mean & $\begin{array}{c}\text { Standard } \\
\text { deviation }\end{array}$ & Median & $\begin{array}{c}\text { Range } \\
\text { IQ 25-75 }\end{array}$ \\
\hline $\begin{array}{l}\text { Overall } \\
\text { environment }\end{array}$ & 106.8 & 13.98 & 109.4 & $98.5-116$ \\
Autonomy & 36.57 & 5.69 & 37 & $33-40$ \\
Support & 30.48 & 2.48 & 31 & $28-34$ \\
Teaching & 39.79 & 6.14 & 41 & $35.5-43.5$ \\
\hline
\end{tabular}

TABLE 3. Results of the Maslach Burnout Inventory

\begin{tabular}{lcccc}
\hline & Mean & $\begin{array}{c}\text { Standard } \\
\text { deviation }\end{array}$ & Median & $\begin{array}{c}\text { Range } \\
\text { IQ 25-75 }\end{array}$ \\
\hline Exhaustion & 27.14 & 10.37 & 2720 & $5-34.5$ \\
Depersonalization & 10.73 & 6.51 & 10 & $5-16$ \\
Accomplishment & 37.01 & 4.82 & 38 & $34-40.5$ \\
\hline
\end{tabular}


TABLE 4. Population as per presence of burnout*

\begin{tabular}{|c|c|c|c|}
\hline & $\begin{array}{c}\text { Burnout Yes= } 18 \\
(19.6 \%)\end{array}$ & $\begin{array}{c}\text { Burnout } \mathrm{No}=74 \\
(80.4 \%)\end{array}$ & $\begin{array}{c}\text { Significance }^{* *} \\
\mathrm{p}<0.05\end{array}$ \\
\hline \multicolumn{4}{|l|}{ Specialty } \\
\hline 1 & 4 & 25 & $\mathrm{p}=0.143$ \\
\hline 2 & 5 & 15 & \\
\hline 3 & 1 & 13 & \\
\hline 4 & 6 & 8 & \\
\hline 5 & 2 & 13 & \\
\hline \multicolumn{4}{|l|}{ Year } \\
\hline 1 & 9 & 31 & $p=0.526$ \\
\hline 2 & 5 & 14 & \\
\hline 3 & 3 & 15 & \\
\hline 4 & 1 & 14 & \\
\hline \multicolumn{4}{|l|}{ Sex } \\
\hline Female & 13 & 51 & $\mathrm{p}=0.514$ \\
\hline Male & 5 & 23 & \\
\hline \multicolumn{4}{|l|}{ Nationality } \\
\hline Argentine & 15 & 65 & $\mathrm{p}=0.429$ \\
\hline Foreign & 3 & 9 & \\
\hline \multicolumn{4}{|l|}{ Coexistence } \\
\hline Alone & 7 & 26 & $\mathrm{p}=0.484$ \\
\hline Accompanied & 11 & 48 & \\
\hline Environment ${ }^{* * *}$ & $\begin{array}{c}98.7 \\
(92.5-104.9)\end{array}$ & $\begin{array}{c}108.8 \\
(105.6-111.9)\end{array}$ & $\mathrm{p}=0.0056$ \\
\hline
\end{tabular}

* Burnout Yes $=$ exhaustion $>26$, despersonalization $>9$ and accomplishment $<34$.

** Categorical outcome measures: X2, continuous outcome measures: $t$ test.

*** Environment: mean (95\% confidence interval).

TABLE 5. Correlation among overall environment and the pheem subscales (autonomy, teaching and support) and the three mbi subscales (exhaustion, depersonalization and accomplishment)

\begin{tabular}{lcccc}
\hline & Overall environment & Autonomy & Support & Teaching \\
\hline Exhaustion & $\mathbf{- 0 . 2 4 3} \mathrm{p}=\mathbf{0 . 0 1 9 6}$ & $\mathbf{- 0 . 5 7 8 6} \mathrm{p}=\mathbf{0 . 0 0 0}$ & $0.0014 \mathrm{p}=0.989$ & $-0.0821 \mathrm{p}=0.4366$ \\
Depersonalization & $\mathbf{- 0 . 3 5 3 5} \mathrm{p}=\mathbf{0 . 0 0 0 5}$ & $\mathbf{- 0 . 4 0 5 1} \mathrm{p}=\mathbf{0 . 0 0 0 1}$ & $0.0136 \mathrm{p}=0.898$ & $\mathbf{- 0 . 2 6 8 2} \mathrm{p}=\mathbf{0 . 0 0 9 8}$ \\
Accomplishment & $\mathbf{0 . 4 4 1} \mathrm{p}=\mathbf{0 . 0 0 0 0}$ & $\mathbf{0 . 4 5 9 3} \mathrm{p}=\mathbf{0 . 0 0 0}$ & $0.1203 \mathrm{p}=0.2532$ & $\mathbf{0 . 3 2 0 4} \mathrm{p}=\mathbf{0 . 0 0 1 8}$ \\
\hline
\end{tabular}

Statistically significant correlations are indicated in bold.

\section{DISCUSSION}

Improving the quality of professional training programs is a continuous challenge for which different approaches have been attempted.

Assessing the EE, understood as a construct that reflects the interrelation between the trainee professional and the different members of the health care team and that also reflects the institutional characteristics defined by the specific "culture" of a setting, is an effective tool to evaluate a residency program.

The EE is an abstract construct that can be indirectly measured using specific instruments. Thus, Roff, et al. ${ }^{13}$ created the Postgraduate Hospital Educational Environment Measure (PHEEM) to assess a context similar to our rotating internship. The PHEEM was validated in Portuguese ${ }^{14}$ and Spanish, ${ }^{15}$ and a multicenter evaluation indicated that it is a highly reliable multidimensional instrument. ${ }^{16}$

Over the past years, the presence of burnout among health care professionals has gained attention, especially among medical residents. $\mathrm{Niku}^{9}$ made a literature review of studies on burnout during the residency and identified 15 studies with different methodological limitations. The average reported prevalence of burnout in varying scenarios is over $50 \%$ of assessed residents. Different studies have associated burnout with the working conditions of doctors and nurses. ${ }^{17,18}$

An attempt has been made to find a relationship between personal features and $\mathrm{BO}$, but no definite conclusions have been stated. ${ }^{19}$ 
Another approach was used by McCray, ${ }^{7}$ who performed a systematic review of studies evaluating interventions that had an impact on the incidence of burnout among residents. McCray's review showed that the prevalence of burnout ranged from $47 \%$ to $76 \%$, with no clear differences observed among clinical and surgical specialties).

Dyrbye, et al. ${ }^{8}$ conducted a multicenter study in five medicine schools and assessed the EE and the presence of burnout among medical students; they concluded that there was an association both in the univariate analysis (OR: 2.07; CI: 1.85-2.31) and in the multivariate analysis (OR: 1.78; CI: 1.47-2.15). Brazeau, et al. ${ }^{20}$ also measured burnout using the MBI, and they confirmed the hypothesis that burnout is inversely correlated with empathy and professionalism.

In a literature review by William, et al. ${ }^{21}$, a burnout prevalence ranging from $27 \%$ to $75 \%$ was found among residents, with differences in relation to their specialty. All these previous literature reports show burnout values higher than those found in our sample (19.6\%); however, it should be noted that we only assessed clinical specialties (pediatrics, general medicine, family medicine, cardiology and intensive care) and, in addition, we used a much stricter definition of burnout when compared to other studies.

Our analysis found significant differences among specialties, both in relation to the EE assessment and the presence of burnout, therefore providing validity to the instruments used and their power to detect differences in the studied outcome measures in varying contexts.

In response to the study's hypothesis, in the analysis of the correlation between the EE (PHEEM) and burnout (MBI), we observed a negative correlation between environment and exhaustion and depersonalization (a poor environment is correlated with higher burnout scores in the corresponding MBI subscales), and a positive correlation between environment and feeling of accomplishment (the better the environment, a higher feeling of accomplishment).

It is even more interesting to have found that the PHEEM autonomy subscale had a more significant correlation, and in the same sense, with the three MBI domains (a negative correlation with exhaustion and depersonalization, and a positive one with accomplishment).

When analyzing which items in the PHEEM autonomy subscale were significant, it was observed that those items are the ones related to an anticipatory behavior (information regarding contents, work load, tasks adequate to training, possibility of acquiring skills) and those related to the sense of group belonging and group dynamics (feeling part of a team, having an atmosphere of mutual respect). These findings are consistent with the factors related to burnout reported by Eckleberry, et al. ${ }^{22}$ in their study on residents. Other authors also found a relationship between autonomy and burnout ${ }^{23}$ and it should be noted that such relationship was also described in non-medical service-related professions. In this regard, Boada, et al. found a positive correlation $(r=0.344)$ between autonomy and personal accomplishment in a group of social workers, administrative staff, teachers and police officers. ${ }^{24}$

Such finding can serve as a major starting point for establishing preventive curricular amendments and structural modifications, which seem to be more effective than intensive stress management strategies. ${ }^{25}$

In addition, such approach could be better than isolated strategies to prevent burnout. No decrease was observed in burnout after an isolated reduction of the work load. ${ }^{26}$

One of this study's limitations was finding only 18 residents who complied with the definition of burout among the 92 surveyed residents. Because of this, it was not possible to confirm significant differences in the presence of burnout, e.g., among specialties or years of residence, in spite of the trends observed in the distribution of frequencies. In addition, a regression analysis with environment dichotomized as an independent outcome measure associated to burnout was performed and the resulting low number of events (residents with burnout) did not allow us to include all demographic outcome measures in the model.

For the same reason, although we found an OR of almost 7 between an environment with a value below its dichotomized median (109.4) and burnout (indicative of an adequate association), the relative low number of residents with burnout translated into a significant dispersion (95\% CI: 1.85-26).

In relation to the study implementation mode, it should be noted that some of the specialties did not include all their residents in the study (general medicine and cardiology); however, it is estimated that there was no selection bias because even with residents assessing their residency program within the institution, strict data anonymity and confidentiality were maintained. An assessment with a larger sample size and 
more specialties (e.g., surgical) could provide more significance to the correlation observed between the EE and burnout.

\section{CONCLUSIONS}

A statistically significant negative correlation was found between the educational environment and exhaustion and depersonalization, and a statistically significant positive correlation was observed between the educational environment and personal accomplishment. A higher EE score was related to less exhaustion and depersonalization and a higher feeling of personal accomplishment.

A higher correlation in the same sense was observed between the PHEEM autonomy subscale and the three MBI subscales.

\section{REFERENCES}

1. Cenn JM, Harden RM. What is medical education here really like? Suggestions for action research studies of climates of medical education environments. Med Teach 1986;8(2):111.

2. Cenn JM. AMEE Medical Education Cuide No. 23 (Part 1): Curriculum, environment, climate, quality and change in medical education-a unifying perspective. Med Teach 2001;23(4):337-44.

3. Cenn JM. AMEE Medical Education Cuide No. 23 (Part 2): Curriculum, environment, climate, quality and change in medical education-a unifying perspective. Med Teach 2001;23(5):445-54.

4. Bris MM. Clima de trabajo y organizaciones que aprenden. Educar 2000;27:103-117.

5. Mc Aleer. A practical guide for Medical Teacher. Edited by Dent J and Harden R. 3 th.Ed. Churchill Livingstone; 2009.

6. Hutchinson L. Educational environment. BMJ 2003;326:810-2.

7. McCray L, Cronholm P, Bogner H, Gallo J, Neill R. Resident Physician Burnout: Is There Hope? Fam Med 2008;40(9):626-32.

8. Dyrbye L, Thomas M, Shanafelt T. Systematic review of depression, anxiety and other indicators of psychological distress among U.S. and canadian medical students. Acad Med 2006;81:354-73.

9. Niku Thomas Resident Burnout. JAMA 2004;292(23):2880-9.

10. Eckleberry J, Lick D, Boura J, Hunt R, et al. An exploratory study of resident burnout and wellness. Acad Med 2009;84(2):269-77.
11. Maslach C, Jackson SE, Leiter MP. Maslach burnout inventory manual. $3^{\circ}$ ed; CPP Inc, 1996.

12. Rafferty JP, Lemkau JP, Purdy RR, Rudisill JR. Validity of the Maslach Burnout Inventory for family practice physicians. J Clin Psychol 1986;42:488-92.

13. RoffS., McAleerS, Skinner A. Development and validation of an instrument to measure postgraduate clinical learning and teaching educational environment for hospitalbased junior doctors in the UK. Med Teach 2005;27(4):326-31.

14. Edson Vieira J. The postgraduate Hospital Educational Environment Measure (PHEEM) questionary identifies quality of instruction as a key factor predicting academic achievement. Clinics 2008;63(6):741-6.

15. Riquelme A, Herrera C, Aranis C, Oporto J, Padilla O. Psychometric analyses and internal consistency of the PHEEM questionnaire to measure the clinical learning environment in the clerkship of a Medical School in Chile. Med Teach 2009;31:6,e:221-5.

16. Wall D, Clapham M, Riquelme A, Vieira J, Cartmill R. Is PHEEM a multidimensional instrument? An international perspective. Med Teach 2009;31:e521-7.

17. Linzer M, Visser M, Oort F. Predicting and preventing physician burnout: results from the United States and the Netherlands. Am J Med 2001;111:170-5.

18. Aiken L, Clarke S, Sloane D, Sochalski J, Silver J. Hospital nurse staffing and patient mortality, nurse burnout and job dissatisfaction. JAMA 1997;288:1987-93.

19. Nyssen A, Hansez I, Baele P, Lamy M, De Keyser V Occupational stress and burnout in anaesthesia. Br JAnaesth 2003;90:333-7.

20. Brazeau C, Schroeder R, Sue R, Boyd L. Relationship between medical student burnout, emphaty, and professionalism climate. Acad Med 2010;85(10)s33-6.

21. William W, Lederer S, Mandili C, Nikravesh R, et al. Burnout during residency training. J Grad Med Educ 2009. Págs.236-42.

22. Eckleberry J, Lick D, Boura J, Hunt R, et al. An exploratory study of resident burnout and wellness. Acade Medic 2009;2:269-77.

23. Ortega Ruiz C, López Ríos F. El burnout o síndrome de estar quemado en los profesionales sanitarios: revisión y perspectivas. Int J Clin Health Psychol 2004;4(1):137-60.

24. Boada J, de Diego Vallejo R, Agulló Tomás E. El burnout y las manifestaciones pscosomáticas como consecuentes del clima organizacional y dela motivación laboral. Psicothema 2004;16(1):125-31.

25. Dyrbye L, Thomas M, Harper W, Massie SF, et al. The learning environment and medical student burnout: a multicentre study. Med Educ 2009;43:274-82.

26. Celfand DV, Podnos YD, Carmichael JC, Saltzman DJ, et al. Effect of the 80-hour workweek on resident burnout. Arch Surg 2004;139 (9):933-8. 


\section{Electronic annex 1. PHEEM Questionnaire}

\begin{tabular}{|c|c|c|c|c|c|}
\hline & $\begin{array}{c}\text { Strong } \\
\text { disagreement }\end{array}$ & Disagreement & Uncertain & Agreement & $\begin{array}{c}\text { Strong } \\
\text { agreement }\end{array}$ \\
\hline \multicolumn{6}{|l|}{$\begin{array}{l}\text { My residency program provides information } \\
\text { about hours of clinical work. }\end{array}$} \\
\hline \multicolumn{6}{|l|}{ My clinical teachers set clear expectations. } \\
\hline \multicolumn{6}{|l|}{$\begin{array}{l}\text { I have protected educational time during this } \\
\text { clinical training. }\end{array}$} \\
\hline \multicolumn{6}{|l|}{ I had an informative induction program. } \\
\hline \multicolumn{6}{|l|}{$\begin{array}{l}\text { I have the appropriate level of responsibility } \\
\text { during this clinical training. }\end{array}$} \\
\hline \multicolumn{6}{|l|}{ I have good clinical supervision at all times. } \\
\hline \multicolumn{6}{|l|}{ There is racism in this clinical training. } \\
\hline \multicolumn{6}{|l|}{$\begin{array}{l}\text { I have to perform tasks that are inappropriate for } \\
\text { my training. }\end{array}$} \\
\hline \multicolumn{6}{|l|}{$\begin{array}{l}\text { There is an informative clinical training handbook } \\
\text { for residents. }\end{array}$} \\
\hline \multicolumn{6}{|l|}{$\begin{array}{l}\text { My clinical teachers have good communication } \\
\text { skills. }\end{array}$} \\
\hline \multicolumn{6}{|l|}{$\begin{array}{l}\text { I am bleeped or called to my mobile } \\
\text { inappropriately. }\end{array}$} \\
\hline \multicolumn{6}{|l|}{$\begin{array}{l}\text { Arrangements are made so that I am able to } \\
\text { participate in educational events without them } \\
\text { interfering with my other classes or exams. }\end{array}$} \\
\hline \multicolumn{6}{|l|}{$\begin{array}{l}\text { There is sex discrimination in this clinical } \\
\text { training. }\end{array}$} \\
\hline \multicolumn{6}{|l|}{$\begin{array}{l}\text { I have clear guidelines about my clinical work in } \\
\text { this training. }\end{array}$} \\
\hline \multicolumn{6}{|l|}{ My clinical teachers are enthusiastic. } \\
\hline \multicolumn{6}{|l|}{$\begin{array}{l}\text { I have good collaboration with other residents in } \\
\text { the same year. }\end{array}$} \\
\hline \multicolumn{6}{|l|}{$\begin{array}{l}\text { My clinical working hours conform to the } \\
\text { requirements. }\end{array}$} \\
\hline \multicolumn{6}{|l|}{$\begin{array}{l}\text { I have the opportunity to provide continuity of } \\
\text { care to patients. }\end{array}$} \\
\hline \multicolumn{6}{|l|}{ I have suitable access to advice. } \\
\hline \multicolumn{6}{|l|}{$\begin{array}{l}\text { This clinical training (hospital/office) has good } \\
\text { quality accommodation for educational events. }\end{array}$} \\
\hline \multicolumn{6}{|l|}{$\begin{array}{l}\text { There is access to an educational program with } \\
\text { explicit objectives relevant to my needs. }\end{array}$} \\
\hline \multicolumn{6}{|l|}{ I get regular feedback from teachers. } \\
\hline \multicolumn{6}{|l|}{ My clinical teachers are well organized. } \\
\hline \multicolumn{6}{|l|}{$\begin{array}{l}\text { I feel physically safe within the clinical } \\
\text { environment (hospital/office). }\end{array}$} \\
\hline \multicolumn{6}{|l|}{$\begin{array}{l}\text { There is a no-blame culture in this clinical } \\
\text { training. }\end{array}$} \\
\hline \multicolumn{6}{|l|}{ There are adequate catering facilities. } \\
\hline $\begin{array}{l}\text { I have enough clinical learning opportunities for } \\
\text { my needs. }\end{array}$ & & & & & \\
\hline
\end{tabular}




\begin{tabular}{l|l|l|l|l|l} 
& $\begin{array}{c}\text { Strong } \\
\text { disagreement }\end{array}$ & Disagreement & Uncertain & Agreement & $\begin{array}{c}\text { Strong } \\
\text { agreement }\end{array}$ \\
\hline My clinical teachers have good clinical skills. & & & & & \\
\hline I feel part of a working team here. & & & & & \\
\hline $\begin{array}{l}\text { I have opportunities to acquire the appropriate } \\
\text { practical procedures for my level. }\end{array}$ & & & & & \\
\hline My clinical teachers are accessible. & & & & & \\
\hline My workload in this clinical training is adequate. & & & & & \\
\hline $\begin{array}{l}\text { My teachers utilize learning opportunities } \\
\text { effectively. }\end{array}$ & & & & & \\
\hline $\begin{array}{l}\text { The training in this residency makes me feel ready } \\
\text { to become a medical doctor. }\end{array}$ & & & & & \\
\hline My clinical teachers have good mentoring skills. & & & & & \\
\hline $\begin{array}{l}\text { I have enjoyment time outside this clinical training. } \\
\text { My clinical teachers encourage me to be an } \\
\text { independent learner. }\end{array}$ & & & & & \\
\hline $\begin{array}{l}\text { There are good counseling opportunities for } \\
\text { residents who fail to complete their clinical training } \\
\text { satisfactorily. }\end{array}$ & & & & & \\
\hline $\begin{array}{l}\text { The clinical teachers provide me with good } \\
\text { feedback on my strengths and weaknesses. }\end{array}$ & & & & & \\
\hline $\begin{array}{l}\text { My clinical teachers promote an atmosphere of } \\
\text { mutual respect. }\end{array}$ & & & & & \\
\hline
\end{tabular}

\section{INTERPRETING PHEEM SCORES}

The overall environment assessment can be interpreted as follows:

0 to 40 : very poor

41 to 80: plenty of problems

81 to 120 : more positive than negative

121 to 160: excellent

The autonomy subscale can be interpreted as follows:

Items: 1, 4, 5, 8, 9, 11, 14, 17, 18, 29, 30, 32, 34, 40
0 to 14 : very poor
15 to 28: negative
29 to 42 : positive

43 to 56 : excellent

The support subscale can be interpreted as follows:

Items: 7, 13, 19, 20, 24, 25, 26, 35, 38

0 to 11: non-existent

12 to 22 : not a pleasant place

23 to 33: more pros than cons

34 to 44: a good supportive environment

The teaching subscale can be interpreted as follows:

Items: 2, 3, 6, 10, 12, 15, 21, 22, 23, 27, 28, 31, 33, 37, 39

0 to 15 : very poor

16 to 30: in need of review

31 to 45 : moving in the right direction

46 to 60: model teachers

Items $7,8,11$ and 13 are scored reversely. 


\section{Electronic annex 2. Maslach Burnout Inventory (MBI)}

\begin{tabular}{|c|c|c|c|c|c|c|c|c|}
\hline & & Never & $\begin{array}{l}\text { A few times } \\
\text { a year or less }\end{array}$ & $\begin{array}{l}\text { Monthly } \\
\text { or less }\end{array}$ & $\begin{array}{l}\text { A few } \\
\text { times } \\
\text { a month }\end{array}$ & $\begin{array}{l}\text { Every } \\
\text { week }\end{array}$ & $\begin{array}{l}\text { A few } \\
\text { times } \\
\text { a week }\end{array}$ & Every day \\
\hline & & 0 & 1 & 2 & 3 & 4 & 5 & 6 \\
\hline 1 & $\begin{array}{l}\text { I feel emotionally drained from my } \\
\text { work. }\end{array}$ & & & & & & & \\
\hline 2 & $\begin{array}{l}\text { I feel drained at the end of the } \\
\text { workday. }\end{array}$ & & & & & & & \\
\hline 3 & $\begin{array}{l}\text { I feel fatigued when I get up in the } \\
\text { morning and have to face another } \\
\text { day on the job. }\end{array}$ & & & & & & & \\
\hline 4 & $\begin{array}{l}\text { I can easily understand how my } \\
\text { patients feel about things. }\end{array}$ & & & & & & & \\
\hline 5 & $\begin{array}{l}\text { I feel I treat some of my patients as } \\
\text { if they were objects. }\end{array}$ & & & & & & & \\
\hline 6 & $\begin{array}{l}\text { Working with patients every day } \\
\text { is a strain for me. }\end{array}$ & & & & & & & \\
\hline 7 & $\begin{array}{l}\text { I deal very effectively with the } \\
\text { problems of my patients. }\end{array}$ & & & & & & & \\
\hline 8 & I feel "burned out" from my work. & & & & & & & \\
\hline 9 & $\begin{array}{l}\text { I feel I am positively influencing } \\
\text { other people's lives through my } \\
\text { work. }\end{array}$ & & & & & & & \\
\hline 10 & $\begin{array}{l}\text { I have become more callous toward } \\
\text { people since I took this job. }\end{array}$ & & & & & & & \\
\hline 11 & $\begin{array}{l}\text { I worry that this job is hardening me } \\
\text { emotionally. }\end{array}$ & & & & & & & \\
\hline 12 & I feel very energetic. & & & & & & & \\
\hline 13 & I feel frustrated by my job. & & & & & & & \\
\hline 14 & $\begin{array}{l}\text { I feel I am working too hard on } \\
\text { my job. }\end{array}$ & & & & & & & \\
\hline 15 & $\begin{array}{l}\text { I do not really care what happens } \\
\text { to some of my patients. }\end{array}$ & & & & & & & \\
\hline 16 & $\begin{array}{l}\text { Working with patients directly puts } \\
\text { too much stress on me. }\end{array}$ & & & & & & & \\
\hline 17 & $\begin{array}{l}\text { I can easily create a relaxed } \\
\text { atmosphere with my patients. }\end{array}$ & & & & & & & \\
\hline 18 & $\begin{array}{l}\text { I feel exhilarated after working } \\
\text { closely with my patients. }\end{array}$ & & & & & & & \\
\hline 19 & $\begin{array}{l}\text { I have accomplished many } \\
\text { worthwhile things in this job. }\end{array}$ & & & & & & & \\
\hline 20 & $\begin{array}{l}\text { I feel I am at the end of my rope in } \\
\text { my job. }\end{array}$ & & & & & & & \\
\hline 21 & $\begin{array}{l}\text { I feel I can deal with emotional } \\
\text { problems adequately in my job. }\end{array}$ & & & & & & & \\
\hline 22 & $\begin{array}{l}\text { I feel patients blame me for some of } \\
\text { their problems. }\end{array}$ & & & & & & & \\
\hline
\end{tabular}


Emotional exhaustion subscale. It is made up of 9 questions. It assesses feeling emotionally exhausted from work demands. Maximum score: 54 . It covers items 1, 2, 3, 6, 8, 13, 14, 16 and 20. This score is directly proportional to BO severity. With a maximum score of 54 , the higher the score in this subscale, the higher the emotional exhaustion and $\mathrm{BO}$ experienced by the subject.

Depersonalization subscale. It is made up of 5 items: 5, 10, 11, 15 and 22. It assesses the degree of distancing and indifference admitted by the subject. With a maximum score of 30 , the higher the score in this subscale, the higher the depersonalization and $\mathrm{BO}$ experienced by the subject.

Personal accomplishment subscale. It is made up of 8 items. It assesses feelings of self-efficacy and personal accomplishment at work. Personal accomplishment covers items 4, 7, 9, 12, 17, 18, 19 and 21. With a maximum score of 48 , the higher the score in this subscale, the higher the personal accomplishment, because in this case the score is reversely proportional to the level of $\mathrm{BO}$. That is to say, a lower personal accomplishment score indicates that the subject is more affected by BO. 